\title{
Quitting Breastfeeding Very Early after Caesarean Section-A Worrying Trend in Babylon Province
}

\author{
Sijal Fadhil Farhood $^{\mathrm{a}} \quad$ Ihab Raad Abbas $^{\mathrm{b}} \quad$ Usama Harba $^{\mathrm{c}}$ \\ ${ }^{a}$ Department of Community Medicine,University of Babylon, College of Medicine. \\ bDepartment of Obstetrics and Gynecology, Hilla General Teaching Hospital \\ ${ }^{c}$ Ministry of Health,Babylon Directorate of Health Technical Department \\ sijalaljoborae@yahoo.com 78sijal@gmail.com Dr_harba@yahoo.com
}

Submission date:- 7/3/2018 Acceptance date:- 4/4/2018 Publication date:- 14/10/2018

Keywords: Breast feeding, Caesarean section, Early infancy.

\begin{abstract}
A cross sectional study was conducted in Al-Hilla City, Babylon Province, Iraq, of 300 women who gave birth via Cesarean section at the two main maternity surgical wards in the city from a period from 1st of December 2017 to $15^{\text {th }}$ of March , 2018. The mothers came from mixed urban and rural backgrounds. Socio -demographic and obstetric data were recorded. Neonatal data was extracted from the medical records of the labor and neonatal care wards. The study included mothers of all ages, one fifth $(23 \%)$ of whom were teenagers and minors marrying at a very young age (31\%). Unfortunately (64\%) had poor or negative attitudes to breastfeeding. Lack of motivation and self-confidence are also major reasons for very early cessation of breastfeeding. This study cited that the Cesarean section per se is a major cause of quitting natural feeding .The patients were influenced by advice from not only close relatives but also doctors and health personnel after the Caesarean section.
\end{abstract}

\section{1- Introduction}

Since the end of the last century the cesarean rate in Babylon Province has been on the increase. It is common for a local maternity ward to report more than 2 in 5 births place via cesarean section. This rate will probably continue to undergo a very significant increase in the next few years as more and more teenage and underage mothers are marrying younger. Therefore, many mothers are having to cope with having a cesarean just as they are also trying to care for their newborn infants[1].

One area which cesareans affect significantly is breastfeeding. The sheer physical impact of trying to recover from major surgery while taking care of a newborn baby is often overwhelming, and the emotional impact can be devastating as well. Research shows fewer women breastfeed their babies after having had a cesarean. Stress tends to delay lactogenesis, and routine protocols and medicines that surround cesareans tend to interfere with breastfeeding initiation and decrease supply[2].

Mothers who have had a cesarean need more support and help to establish breastfeeding. However, local hospitals lack proper breastfeeding support to women who have had a cesarean and not all women receive timely help or emotional support after birth, and so breastfeeding is not initiated properly. In addition to this, some mothers unfortunately have hormonal, genetic, or infant medical ailments that may prevent them from breastfeeding their babies fully[3]. In summary, the study findings demonstrate that breastfeeding is the best feeding option for both mother and infant. However, women often encounter barriers to breastfeeding, even after successful breastfeeding initiation, which may put them at greater risk for early cessation of breastfeeding.

\section{2- Objectives}

1-To examine factors related to very early discontinuation of breastfeeding by mothers who give birth via a caesarean in Babylon Province.

2-To offer an insight why mothers are struggling with breastfeeding problems immediately after the section and how they can overcome them.

3- It aims to impact local hospital staff practices and guidelines positively to provide a plan of action that advocates breastfeeding, and minimize problems. 


\section{3-Patients and Methods}

A cross sectional study was conducted in Al-Hilla City, Babylon Province, Iraq, of 300 women who gave birth via Cesarean section at the two main maternity surgical wards in the city from period from 1 st of December 2017 to $15^{\text {th }}$ of March , 2018.

The inclusion criteria include:

1) All women who gave birth exclusively via Ceasarean section .

2) Residents of Babylon province.

3)The decision of quitting breastfeeding was taken immediately after the section.

All participants were informed of the purpose, requirements and procedures of the study. They were also informed that their participation in the study was voluntary. A self-structured questionnaire sheet was designed by the author and it included:

Current maternal age, Age at marriage, Residence ,Education, Employment, Family history, Gravida, Parity, Previous Caesarean section, Number of babies. Spacing between births, Family planning methods, When the mother plans to return to work, Pregnancy and birth history, Type of Caesarean section, Baby gender, Period of staying in hospital after the section ,Whether the new born infant was separated from the mother at the SCBU for prematurity and or LBW, Previous procedures related to the breast, History of Premature labor, High blood pressure,Gestational diabetes mellitus, Urinary tract infection,Anemia, Severe nausea/vomiting, Breast feeding history and reasons for not breastfeeding .The following were inquired about:

1-Presence of Medical problems (malnourished mother, diabetic).

2-Nipple problems (Inverted nipple, dermatitis, mastitis, cracked).

3-Poor quality of milk (not enough milk, bad taste, less nutritive).

4- Having no practice of breast feeding.

5-Working mothers or heavy duties at home.

6-Advice of the doctor / medical staff:

7-Pressure from non-medically qualified persons (close relatives, neighbors, friends).

8 -Her breast milk causes jaundice or chronic diarrhea.

9-Low birth weight and prematurity.

10- Whether her child refuses breastfeed.

11-Psychological problems and marital discord.

12-Mother being still a student.

13-Presence of neonatal metabolic disorder (IEM).

14-Whether her previous child did not thrive on breast milk.

15-Others (The father passed away, use of contraceptive pills, multiple births).

Finally they were asked whether they considered introducing non formula milk(Raw milk (cow, buffalo, goat), full fat adult milk etc.) before her child reaches the first year of age.

\section{4-Ethical Approval:}

Ethical issues of this study depend oo the following

1- Approval of the Scientific Committee of Community Medicine-College of Medicine Babylon University.

2- The objective and methodology of this study were explained to all participants in the study to gain their verbal acceptance.

\section{5-Data Analysis:}

Recorded information was checked for missing values and data entry errors. Statistical analysis was performed using Statistical Package for Social Science software (SPSS, version 20). Variables were described using frequency distribution and percentage for the patients according to their characteristics. Chi square test was used for the assessment of the association between the variables studied. A p- value of less than 0.05 was significant statistically. 
6- Results:

Table1: Demographic Characteristics of Mothers Included in the Study $(n=300)$.

\begin{tabular}{|c|c|c|}
\hline $\begin{array}{r}\text { VARIABLES } \\
\end{array}$ & NUMBER & PERCENTAGE $(\%)$ \\
\hline $\begin{array}{l}\text { Current Maternal Age(year) } \\
<18 \\
18-35 \\
\geq 35 \\
\text { Total }\end{array}$ & $\begin{array}{c}69 \\
192 \\
39 \\
300\end{array}$ & $\begin{array}{c}23.0 \\
64.0 \\
13.0 \\
100.0\end{array}$ \\
\hline $\begin{array}{l}\text { Maternal Age at Marriage(year) } \\
<18 \\
18-35 \\
\geq 35 \\
\text { Total }\end{array}$ & $\begin{array}{c}93 \\
195 \\
12 \\
300\end{array}$ & $\begin{array}{c}31.0 \\
65.0 \\
4.0 \\
100.0\end{array}$ \\
\hline $\begin{array}{l}\text { Maternal Education } \\
\text { Illiterate } \\
\text { Primary education } \\
\text { Secondary education } \\
\text { Higher education } \\
\text { Total }\end{array}$ & $\begin{array}{c}27 \\
207 \\
42 \\
24 \\
300 \\
\end{array}$ & $\begin{array}{c}9.0 \\
69.0 \\
14.0 \\
8.0 \\
100.0 \\
\end{array}$ \\
\hline $\begin{array}{l}\text { Maternal employment } \\
\text { Employed } \\
\text { Unemployed } \\
\text { Total }\end{array}$ & $\begin{array}{c}57 \\
243 \\
300\end{array}$ & $\begin{array}{c}19.0 \\
81.0 \\
100.0\end{array}$ \\
\hline $\begin{array}{l}\text { Residence } \\
\text { Urban } \\
\text { Rural } \\
\text { Total }\end{array}$ & $\begin{array}{l}174 \\
126 \\
300\end{array}$ & $\begin{array}{c}58.0 \\
42.0 \\
100.0\end{array}$ \\
\hline $\begin{array}{l}\text { Employed Mothers Returning to Work } \\
(\mathbf{n}=\mathbf{5 7}) \\
\text { Within } 30 \text { days } \\
6 \text { months } \\
1 \text { year } \\
\text { Total }\end{array}$ & $\begin{array}{c}12 \\
39 \\
6 \\
57 \\
\end{array}$ & $\begin{array}{c}21.0 \\
68.4 \\
10.6 \\
100.0 \\
\end{array}$ \\
\hline
\end{tabular}

Table 1 shows the demographic characteristics of mothers included in the Study $(n=300) .23 \%$ of mothers in the study were under 18 years of age. $78 \%$ of them were either illiterate or had no more than a primary level of education. $19 \%$ of mothers were employed, and a minority took a whole year maternal leave $10.6 \%$.

Table2: Obstetrical, gynecological and surgical history of the mothers included in the study $(\mathrm{n}=300)$.

\begin{tabular}{||l|c|c||}
\hline \multicolumn{1}{|c|}{ VARIABLES } & NUMBER & PERCENTAGE(\%) \\
\hline Gravida & & 30.0 \\
One & 90 & 26.0 \\
Two & 78 & 44.0 \\
$>$ two & 132 & 100.0 \\
Total & 300 & 70.0 \\
\hline Previous caesarian section (n=210 ) & & 30.0 \\
Yes & 147 & 100.0 \\
No & 63 & \\
Total & 210 & 92.0 \\
& & 8.0 \\
Number of baby & & 100.0 \\
Single & 276 & 24 \\
Multiple & 300 & \\
Total & & \\
\hline
\end{tabular}




\begin{tabular}{||l|c|c||}
\hline Spacing between pregnancies (n=210 ) & & \\
$<2$ years & 132 & 62.8 \\
$\geq 2$ years & 78 & 37.2 \\
Total & 210 & 100.0 \\
& & \\
& & \\
\hline Family planning method planned to be & & 3.0 \\
used* & 9 & 83.0 \\
Barriers & 249 & 2.0 \\
Pills & 6 & 11.0 \\
NFP* & 33 & 1.0 \\
IUCD* & 3 & 100.0 \\
LAM* & 300 & 25.0 \\
Total & & 75.0 \\
\hline Type of Caesarean section & 75 & 100.0 \\
Emergency & 225 & 94.0 \\
Planned & 300 & 6.0 \\
Total & & 100.0 \\
\hline Period of maternal hospital stay(hr) & 282 & 3.0 \\
< 48 & 18 & 97.0 \\
$\geq 48$ & 300 & 100.0 \\
Total & & \\
\hline Breast Procedures? & 9 & \\
Yes & 291 & \\
No & 300 & \\
Total & & \\
& & \\
\hline
\end{tabular}

*NFP:Natural family planning, IUCD: Intra uterine contraceptive device, LAM: Lactational amenorrhea method Table (2) shows that $30 \%$ of mothers who quitted breastfeeding were first time mothers who had no children before. Of those who have more than one child $70 \%$ had a previous Cesarean section. Only $3 \%$ had a history of a surgical procedure in their breasts.

Table 3: Infantile variables in the study $(n=300)$.

\begin{tabular}{|c|c|c|}
\hline VARIABLES & NUMBER & PERCENTAGE(\%) \\
\hline $\begin{array}{l}\text { Gender } \\
\text { Male } \\
\text { Female } \\
\text { Total }\end{array}$ & $\begin{array}{l}156 \\
144 \\
300\end{array}$ & $\begin{array}{c}52.0 \\
48.0 \\
100.0\end{array}$ \\
\hline $\begin{array}{l}\text { Baby being cared for in the SCBU* } \\
\text { Yes } \\
\text { No } \\
\text { Total }\end{array}$ & $\begin{array}{c}72 \\
228 \\
300\end{array}$ & $\begin{array}{c}24.0 \\
76.0 \\
100.0\end{array}$ \\
\hline
\end{tabular}

*SCBU: Special care baby unit. Table (3) indicates that one quarter of infants born via Caesarean section were cared for in the local special care baby unit. 
Table 4: Causes behind mothers who opt out of breastfeeding $(n=300)$.

\begin{tabular}{|c|c|c|}
\hline CAUSES & NUMBER & PERCENTAGE(\%) \\
\hline $\begin{array}{l}\text { 1-Misperceptions about quality of milk (not enough milk, bad taste, less nutritive } \\
\text { etc.) }\end{array}$ & 87 & 29.0 \\
\hline 2-Medical problems (malnourished mother, diabetic) & 12 & 4.0 \\
\hline $\begin{array}{l}\text { 3-Nipple problems (Inverted/cracked nipple, } \\
\text { dermatitis, mastitis) }\end{array}$ & 3 & 1.0 \\
\hline 4- Have no practice of breast feeding & 3 & 1.0 \\
\hline 5-Working mothers or heavy duties at home & 3 & 1.0 \\
\hline 6-Wrong advice of the doctor / medical staff immediately after C-section. & 6 & 2.0 \\
\hline $\begin{array}{l}\text { 7-Pressure from non-medically qualified persons (close relatives, neighbors, } \\
\text { friends) }\end{array}$ & 6 & 2.0 \\
\hline 8-Breast milk causes jaundice or chronic diarrhea & 21 & 7.0 \\
\hline 9-Low birth weight and prematurity & 66 & 22.0 \\
\hline 10- Child refuses to breast feed & 42 & 14.0 \\
\hline 11-Psychological problems and marital discord & 6 & 2.0 \\
\hline 12-Mother is still a student & 3 & 1.0 \\
\hline 13-Neonatal metabolic disorder (IEM) & 18 & 6.0 \\
\hline 14-Her previous child did not thrive on breast milk & 3 & 1.0 \\
\hline 15-Others (The father passed away, use of contraceptive pills, multiple births) & 21 & 7.0 \\
\hline Total & 300 & 100.0 \\
\hline
\end{tabular}

Table 4 shows the causes behind mothers who opt out of breast feeding which can divided into three main causes ;maternal medical problems(33\%), social issue(27\%) and neonatal related issues(40\%).

Table5: Medical problems during current pregnancy of the mothers who opt out breast feeding (n=300).

\begin{tabular}{||l|c|c||}
\hline \hline MEDICAL PROBLEMS & NUMBER & PERCENTAGE(\%) \\
\hline Premature labor & 36 & 12.0 \\
High blood pressure & 27 & 9.0 \\
Gestational D.M & 6 & 2.0 \\
Anemia $\quad$ nausea/vomiting & 129 & 43.0 \\
UTI & 63 & 21.0 \\
Total & 39 & 13.0 \\
& 300 & 100.0 \\
\hline
\end{tabular}

Table 6: The Association between Causes of Very Early Discontinuation of Breast feeding and Maternal Demographic factors $(n=300)$.

\begin{tabular}{|c|c|c|c|c|c|c|}
\hline \multirow[t]{2}{*}{ VARIABLES } & \multicolumn{3}{|c|}{$* *$ CAUSES } & \multirow[t]{2}{*}{ TOTAL } & \multirow[t]{2}{*}{$\mathrm{X}^{2}$} & \multirow[t]{2}{*}{ P-VALUE } \\
\hline & $\begin{array}{l}\text { Maternal } \\
\text { medical } \\
\text { problems }\end{array}$ & $\begin{array}{l}\text { Social } \\
\text { issues }\end{array}$ & $\begin{array}{l}\text { Neonatal } \\
\text { related causes }\end{array}$ & & & \\
\hline $\begin{array}{l}\text { Current maternal/care } \\
\text { giver age(year) } \\
<\mathbf{1 8} \\
\mathbf{1 8 - 3 5} \\
\geq \mathbf{3 5} \\
\text { Total } \\
\end{array}$ & $\begin{array}{r}18(6.0 \%) \\
63(21.0 \% \\
18(6.0 \%) \\
99(33.0 \%) \\
\end{array}$ & $\begin{array}{l}21(7.0 \%) \\
54(18.0 \% \\
6(2.0 \%) \\
81(27.0 \%) \\
\end{array}$ & $\begin{array}{c}30(10.0 \%) \\
75(25 \%) \\
15(5.0 \%) \\
120(40.0 \%) \\
\end{array}$ & $\begin{array}{c}69(23.0 \%) \\
192(64.0 \%) \\
39(13.0 \%) \\
300(100.0 \%) \\
\end{array}$ & 5.660 & 0.226 \\
\hline $\begin{array}{l}\text { Maternal age at } \\
\text { marriage(year) } \\
<\mathbf{1 8} \\
\mathbf{1 8 - 3 5} \\
\geq \mathbf{3 5} \\
\text { Total }\end{array}$ & $\begin{array}{c}27(9.0 \%) \\
69(23.0 \%) \\
3(1.0 \%) \\
99(33.0 \%)\end{array}$ & $\begin{array}{c}36(12.0 \%) \\
45(15.0 \%) \\
0(0.0 \%) \\
81(27.0 \%)\end{array}$ & $\begin{array}{c}30(10.0 \%) \\
81(27.0 \%) \\
9(3.0 \%) \\
120(40.0 \%)\end{array}$ & $\begin{array}{c}93(31.0 \%) \\
195(65.0 \%) \\
12(4.0 \%) \\
300(100.0 \%)\end{array}$ & 14.757 & $* 0.002^{\mathrm{f}}$ \\
\hline
\end{tabular}




\begin{tabular}{|c|c|c|c|c|c|c|}
\hline $\begin{array}{l}\text { Maternal education } \\
\text { Illiterate } \\
\text { Primary } \\
\text { Secondary } \\
\text { Higher education } \\
\text { Total }\end{array}$ & $\begin{array}{l}0(0.0 \%) \\
81(27.0 \%) \\
15(5.0 \%) \\
3(1.0 \%) \\
99(33.0 \%)\end{array}$ & $\begin{array}{l}6(2.0 \%) \\
51(17.0 \%) \\
12(4.0 \%) \\
12(4.0 \%) \\
81(27.0 \%)\end{array}$ & $\begin{array}{l}21(7.0 \%) \\
75(25.0 \%) \\
15(5.0 \%) \\
9(3.0 \%) \\
120(40.0 \%)\end{array}$ & $\begin{array}{l}27(9.0 \%) \\
207(69.0 \%) \\
42(14.0 \%) \\
24(8.0 \%) \\
300(100.0 \%)\end{array}$ & 30.413 & $* 0.0001$ \\
\hline $\begin{array}{l}\text { Maternal employment } \\
\text { Employed } \\
\text { Unemployed } \\
\text { Total } \\
\end{array}$ & $\begin{array}{l}15(5.0 \%) \\
84(28.0 \%) \\
99(33.0 \%) \\
\end{array}$ & $\begin{array}{l}18(6.0 \%) \\
63(21.0 \%) \\
81(27.0 \%) \\
\end{array}$ & $\begin{array}{l}24(8.0 \%) \\
96(32.0 \%) \\
120(40.0 \%) \\
\end{array}$ & $\begin{array}{l}57(19.0 \%) \\
243(81.0 \%) \\
300(100.0 \%) \\
\end{array}$ & 1.577 & 0.454 \\
\hline $\begin{array}{l}\text { Residence } \\
\text { Urban } \\
\text { Rural } \\
\text { Total }\end{array}$ & $\begin{array}{l}60(20.0 \%) \\
39(13.0 \%) \\
99(33.0 \%)\end{array}$ & $\begin{array}{c}36(12.0 \%) \\
45(15.0 \%) \\
81(27.0 \%)\end{array}$ & $\begin{array}{l}78(26.0 \%) \\
42(14.0 \%) \\
120(40.0 \%)\end{array}$ & $\begin{array}{l}174(58.0 \%) \\
126(42.0 \%) \\
300(100.0 \%)\end{array}$ & 8.8 & $* 0.012$ \\
\hline
\end{tabular}

${ }^{*}$ f:fisher exact test, ${ }^{*} \mathrm{p}$ value $\leq 0.05$ was significant.

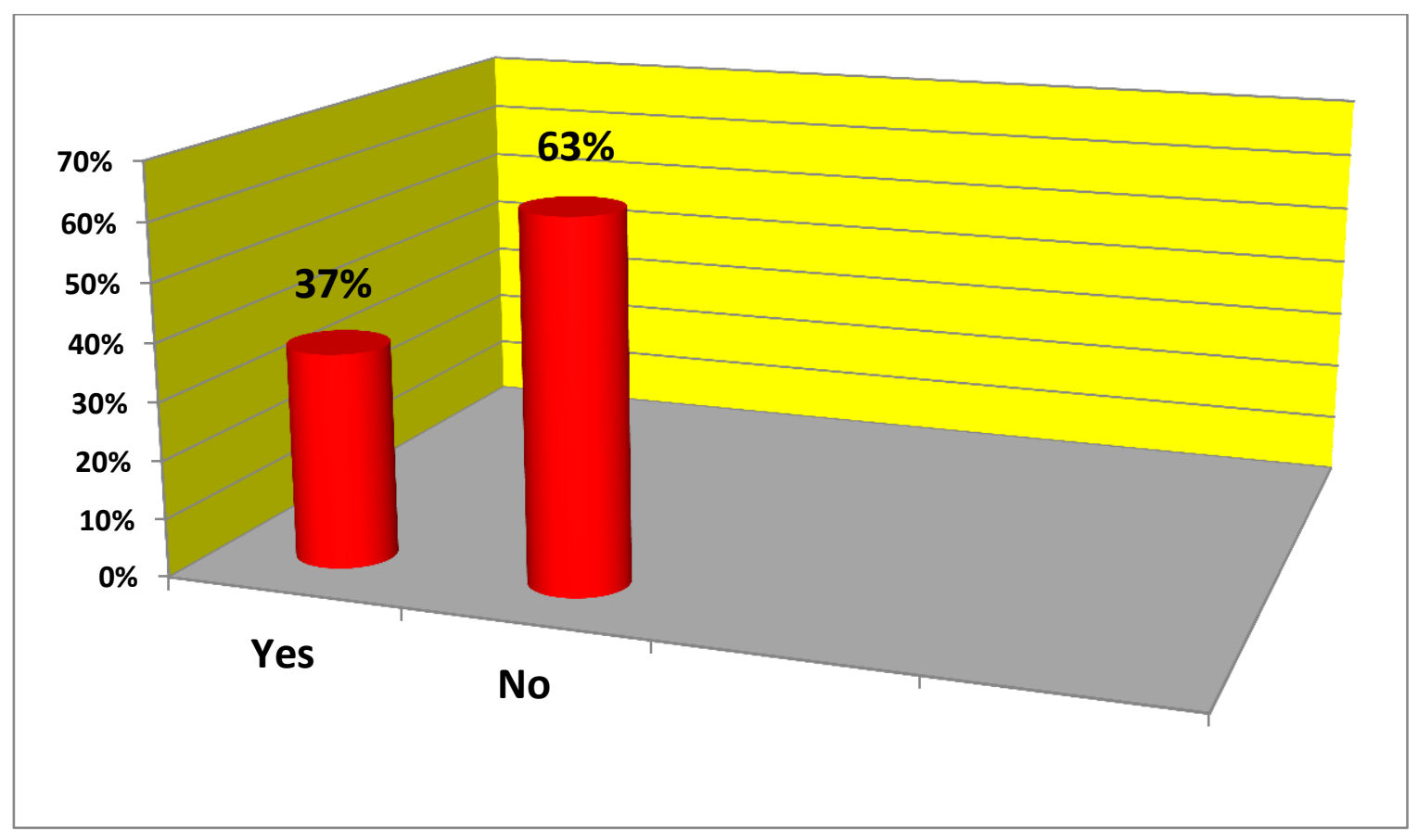

Figure 2: Positive attitudes toward breast feeding $(n=300)$. 


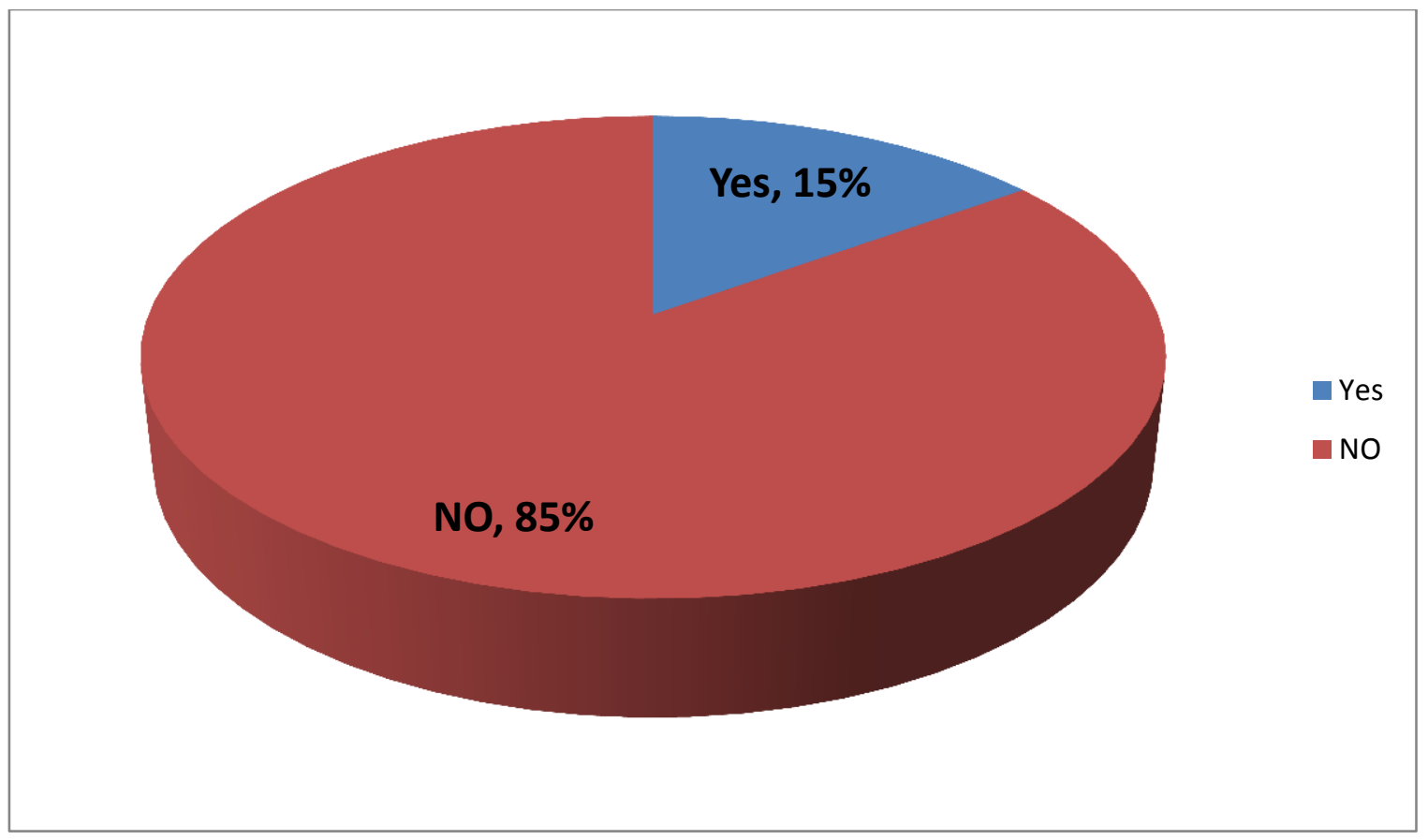

Figure 3: Percentage of women with intention to use non formula milk below one year of age $(\mathbf{n}=300)$.

\section{7- Discussion:}

Breastfeeding rates in general are declining in Babylon Province in Central Iraq, especially among mothers who birth via a Cesarean section. Research clearly shows that breastfeeding initiation rates are lower after a cesarean, and that there is also a significant drop-out rate in the first month after a cesarean[4].Many factors contribute to this lower breastfeeding rate, including the mother's fatigue, pain, and stress levels[5]; type of anesthesia used in the cesarean[6]; routine separation of mother and baby after a cesarean; delayed first nursing and less-frequent later feedings; increased supplementation of cesarean babies; use of bottles, pacifiers and artificial nipples with babies instead of alternatives; labor medication interference with baby's sucking mechanism; intrapartum and postpartum medication interfering with mother's milk supply; postpartum anemia affecting milk supply; and the significant mechanical difficulties of trying to manage nursing after major surgery[7].

The study included mothers of all ages, one fifth (23\%) of whom were teenagers and minors marrying at a very young age $(31 \%)$. Unfortunately $(64 \%)$ had poor or negative attitudes to breastfeeding. Lack of motivation and self-confidence are also major reasons for very early cessation of breastfeeding. These findings are mirrored by the results of a qualitative study that indicate women who a positive attitude and are confident in their ability and committed to breastfeeding are most likely to be successful in their breastfeeding endeavors [8].

In this current study women cited the poor quantity of their breast milk that their bodies produce after a Cesarean section in addition to nipple problems.

Although breastfeeding disparities exist, women across all cultures and socioeconomic status often encounter difficulties that lead to early breastfeeding cessation. Early breastfeeding cessation is commonly influenced by inadequate milk supply, latching difficulties, and painful breasts or clogged milk ducts [9]. Fears of inadequate milk supply, painful breasts, and latching difficulties can be addressed through patient education[10]. Women who participated in a study by [11] reported concerns about insufficient milk supply, painful breasts during feeding, sexuality issues, maternal smoking, contraception, negative self-image, and embarrassment from public breastfeeding as reasons for early cessation.

An international study examined the impact of cesarean delivery on the initiation and duration of breastfeeding among 2517 Mexican women. Multivariate Logistic Regression was used to determine the odds ratio of cesarean mothers not initiating breastfeeding (odds ratio=.64) or for breastfeeding less than one month (odds ratio=.58). Cesarean section was found to be a very significant factor in impacting breastfeeding rates.[12] 
It is a well-known fact that natural breast feeding help hasten uterine involution after a Cesarean section. Unfortunately women in Babylon who opt out of breastfeeding have more obstetric complications and re-hospitalization after initial discharge from the local maternity wards in our Province. In addition to faster uterine involution, breastfeeding helps quicker weight loss after birth [13].Cesarean babies who are breastfed also receive significant benefits such as immunological protections, and prevention/minimization of hypoglycemia and jaundice problems. The cesarean mother/baby duo often finds that breastfeeding is extremely healing emotionally after a difficult birth and can do much to help the pair bond under trying circumstances. Many cesarean mothers report that being able to breastfeed their child afterwards was one of the most healing things they were able to do for themselves [14].

It is common finding in our wards for supplementary formula milk to be at the bedside immediately after birth. This finding is widespread in other socities. Many cesarean babies are given bottles of formula routinely [15] which research clearly shows also lowers the rate and duration of successful breastfeeding [16]. Blomquist [17] (1994) found that, "Infants given a supplementary feeding had 4 times the risk of not being breastfed at 3 months." [18]found that "30\% of mothers whose babies received bottles in the hospital reported severe breastfeeding problems, as compared with $14 \%$ of those whose babies did not." This study cited that the Cesarean section per se is a major cause of quitting natural feeding .The patients were influenced by advice from not only close relatives but doctors and health personnel after the Caesarean section as shown in table [19]. International research clearly shows that after a cesarean, fewer women initiate breastfeeding at all, or give up within the first month. DiMatteo (1996)[20] also showed that women who had a cesarean had lower breastfeeding rates.

Some mothers were deprived of the benefit to see their neonates after a Cesarean section. The longer the separation the more likely these mothers quitted breastfeeding. In our study the reasons for prolonged separation included hospitalization for prematurity and low birth weight among others. Global studies indicated that earlier nursing as soon as possible after birth ensures the jumpstarting of hormonal processes designed to ensure milk supply, and aids in the physical recovery afterwards. Studies show that the most critical issue for breastfeeding success after any birth is early and frequent breastfeeding [21]. Research shows that breastfeeding works best if the first nursing takes place within the first hour after birth. This delay in first nursing can cause critical differences in hormone levels [22] and impact milk supply. It also helps delay the appearance of mature milk [23], putting the baby at risk for dehydration or excessive weight loss after birth, which often leads to supplementary formula. All of this combines to undermine a woman's confidence and desire to breastfeed.

Mothers in our study regarded that colostrum not to be nutritive nor enough to meet the need of their newborns and thus they opted out of breastfeeding immediately after the operation. Colostrum, is extremely high in protective antibodies that help coat gastrointestinal system and protect it from harmful bacteria, and it also contains substances that help 'kickstart' the baby's own immune system. This helps protect the baby faster and is nature's first vaccine." Considering the possible infection risk many cesareans babies face, breastfeeding's immunological protections become especially important.[24]

Because breastfeeding is very much a function of supply and demand, early and frequent breastfeeding is vital for establishing breastfeeding. Studies show that the more the first nursings are delayed, the higher the rate of problems [25]. Similarly, frequent breastfeeding (every 2-3 hours or so) in the first day is important in helping the mature milk to come in more quickly.

The more feedings of colostrum that the baby receives, the more immunological protection the baby gets. In addition, early and frequent breastfeeding can help lessen or treat a baby's tendency towards hypoglycemia and jaundice, problems common after birth scenarios that lead to cesarean [26]. So not only does early and frequent nursing promote earlier 'mature' milk and greater milk supply, it also is protective against many of the problems babies can face after difficult pregnancies or births.

Unfortunately, even in vaginal births many hospitals are hard-pressed to meet this standard, but delays tend to be especially long after a cesarean [27].

In this current study some women cited the presence of a concurrent medical condition that prevented them from nursing their neonates,citing anemia as a major reason. Research shows that women having a cesarean lose about twice the amount of blood as women having a vaginal birth. If a woman experiences excessive blood loss during surgery, she may experience anemia afterwards, which can interfere with milk supply significantly [28].

More women may be anemic postpartum than doctors recognize.[29] found that 27\% of women were anemic postpartum, and that the rate of anemia rose to $43 \%$ among non-Hispanic black women. Yet much of this anemia goes unrecognized and untreated.

Henly (1995) studied the relationship between anemia and insufficient milk syndrome in 630 first-time mothers. They found that $22 \%$ of the mothers were anemic, and of the anemic women, about $20 \%$ reported symptoms of insufficient milk syndrome. These mothers breastfed fully for a shorter period of time and weaned earlier as well. The authors summarized their study by saying, "This study suggests that anemia is associated with the development of insufficient milk, which in turn, is related to duration of full breastfeeding and to age at weaning."[30]

This current study found out that (43\%) of mothers with medical problems suffered from anemia. Women most at risk for anemia postpartum include those who were anemic prenatally; those whose babies were born by cesarean; those who experience a hemorrhage during or after birth; those with certain placental problems like placenta previa, accreta or abruption; women carrying multiples; those with a history of prior post-partum hemorrhage; those with uterine atony; and heavy women (because of extra blood vessels feeding extra tissue) [31]. 
Quitting breastfeeding in our study was also related to intake of medication. An international study [32] used a scoring system to evaluate the effect of medications on neonatal suckling in 129 vaginally-delivered babies. Babies of medicated mothers scored lower in suckling effectiveness than babies of unmedicated mothers, and the scores were lowest in the group that received both epidurals and IV drugs. The overall breastfeeding duration to 6 weeks postpartum was not significantly affected, but even so the authors concluded that:

Labor medications impair suckling in the early postpartum period. Therefore, lactation consultants should be concerned that breastfeeding mothers who have received labor medications may become discouraged, especially if they are discharged before effective breastfeeding is established. If mothers lack adequate support at home or did not receive follow-up care, babies with poor breastfeeding behaviors are at greater risk for dehydration, jaundice, and poor weight gain. [33],[34] found that sucking problems were more common in babies whose mothers had received Demerol. [35] Walker (1997) reviewed a series of studies to determine the effect of labor medications on critical neonatal breastfeeding behaviors and time to first 'successful' breastfeed. She found that IV narcotic medications such as Demerol, Stadol, and Nubain did affect breastfeeding by depressing or delaying behaviors such as rooting and sucking. The longer the infants had been exposed to the medications, the more the feeding behaviors were affected, and generally speaking, the longer until the first 'successful' breastfeed. She noted that every single study reviewed "demonstrated that maternal medication had some effect on the breastfeeding behavior of the baby."

In Babylon epidural route of anesthesia is rarely if ever used for Cesarean section. International studies point out that this mode is a also a contributing factor for opting out of breastfeeding. Epidurals affect newborn behavior, especially in alertness and in disorganized movements[36].However, Walker's review found no studies on epidurals that specifically mentioned breastfeeding as an outcome.

Two studies [37] showed clear depression in motor abilities of medicated babies. Both studies also showed medicated babies exhibited poor state control. The developmental agenda for healthy term infants is that of increasing differentiation and control of states. Medication may delay the process and interfere with the baby's ability to gain control over and modulate state changes in the first 24-48 hours. Drug induced interference may account for the anecdotal descriptions of 'sleepy' babies (babies unable to exhibit enough state control to breastfeed effectively) and further prolong the period of state disorganization.

Other mothers in our study mentioned work as a reason for very early discontinuation of breastfeeding. This is a major social factor that may influence women's decision to discontinue breastfeeding. In fact, maternal employment is often linked to premature weaning due to barriers found in the work environment. According to [38], employed women who return to work after giving birth must cope with the work environment, which includes attitudes of coworkers, length of maternity leave, length of working shifts, and hourly wages or salary. In their study, the researchers found that women who were employed had a $9 \%$ lower rate of breastfeeding at 6 months postpartum than women who were unemployed. Johnston and Esposito also found that supportive work environments increase breastfeeding duration. Women who were offered longer maternity leave were more likely to maintain breastfeeding upon their return to work and reported having an easier transition that combined both their breastfeeding needs and work obligations. Johnston and Esposito's findings are supported by the results of a qualitative study that indicate women who are confident in their ability and committed to breastfeeding are most likely to be successful in their breastfeeding endeavors [39].

Several demographic characteristics have been associated with breastfeeding duration as is shown in this current study the main reason cited being marital discord. Internationally there is an increasing trend for babies to be born to cohabiting and unmarried parents or to single women [40] suggesting many women may not have the support of a spouse or partner. Single women are at greater risk for early breastfeeding cessation. In a study by Kiernan and Pickett [41](2006), a greater degree of parental bonding with the infant of married parents was found to be associated with increased duration of breastfeeding. The father's opinion is often taken into account by the mother in her decision to breastfeed. Women who are both unmarried and parenting alone may not have a support system that helps sustain breastfeeding [42]. Unmarried women are also less likely to quit smoking during pregnancy[43]. Women who smoke have shorter duration of breastfeeding, encounter more difficulties during breastfeeding, and may be more likely to develop depression, which can contribute to breastfeeding difficulties [44].

\section{8- Recommendations}

Breastfeeding offers many benefits to both infants and mothers after cesarean section. We recommend a smoother transition to breastfeeding by mothers being more informed and educated, nursing early and frequently and having access to expert resources.

1-If cesarean is indicated, utilization of alternatives to general anesthesia in our local hospitals.

2-Mothers are encouraged to nurse as early as possible after delivery. They should pursue regular, frequent feedings without a time limit on the breast.

3-Information and imagery should be utilized to help decrease stress and increase milk output, with the support of a professional lactation consultant to help with positioning and latch-on concerns.

4-Avoid artificial nipples and unnecessary supplements as much as possible inside local hospitals.

5-Room in with the baby to increase the breastfeeding success rate. 
A family member or other relative)should room in too, to ease regular feedings.

\section{CONFLICT OF INTERESTS}

There are no conflicts of interest.

\section{References}

[1] Thulier D1, Mercer J.J ."Variables associated with breastfeeding duration". Obstet Gynecol Neonatal Nurs. MayJun;38(3):259-68. 2009.

[2] Avery A1, Zimmermann K, Underwood PW, Magnus JH. "Confident commitment is a key factor for sustained breastfeeding".Birth. Jun;36(2):141-8. 2009.

[3]Rhona J.McInnes,Julie A. Chambers,"Supporting breastfeeding mothers: qualitative synthesis", Journal of Advanced Nursing. 62 (4), pp. 407-427. 2008.

[4] Vivien Swanson BA, Kevin G. Power MA. "Initiation and continuation of breastfeeding: theory of planned behavior" .Journal of Advanced Nursing. 50(3):272-82. 2005.

[5] Taghreed Al Shaban Hassan Bella, Hussain Al Shaban Fadil Aldahan. "Factors affecting Initiation and Exclusivity of Breastfeeding in QATIF”, Saudi ArabiaInnovative Journal of Medical and Health Science, Vol 5, No 5. 2015.

[6] Siskind V, Del Mar C, Schofield F." Infant feeding in Queensland, Australia: long-term trends". Am J Public Health 1993;83:103-106.

[7] Paul Bouvier, André Rougemont. "Breast-feeding in Geneva: Prevalence, duration and determinants.Sozial- und Präventivmedizin", May, Volume 43, Issue 3, 116-123. 1998.

[8] Elizabeth Brand, BSN, Catherine Kothari, MS, and Mary Ann Stark, PhD, RNC.'Factors Related to Breastfeeding Discontinuation Between Hospital Discharge and 2 Weeks Postpartum”.J Perinat Educ. Winter; 20(1): 36-44. 2011.

[9] Ferguson A, Tappin DM, Girdwood RWA, Kennedy R, Cockburn F. “Breast feeding in Scotland”. BMJ;308:824-825. 1994.

[10] Hannula L1, Kaunonen M, Tarkka MT. "A systematic review of professional support interventions for breastfeeding". J Clin Nurs. May;17(9):1132-43.2008.

[11] Donna McCann, PhD, Angelina Barrett et al.'Food additives and hyperactive behaviour in 3-year-old and 8/9-year-old children in the community: a randomised, double-blinded, placebo-controlled trial".Volume 370, No. 9598, p1560-1567, 3 November 2007.

[12] Perez-Escamilla, R et al. "The Association Between Cesarean Delivery and Breast-Feeding Outcomes among Mexican Women”. Am J Public Health. June. 86(6):832-836. 1996.

[13] DiMatteo, MR et al. "Cesarean Childbirth and Psychosocial Outcomes: A Meta-Analysis". Health Psychol. July. 15(4):303-14. 1996.

[14] Indu B. Ahluwalia, Brian Morrow, Jason Hsia."Why Do Women Stop Breastfeeding? Findings From the Pregnancy Risk Assessment and Monitoring System".Pediatrics December, VOLUME 116 / ISSUE 6. 2005.

[15] American Academy of Pediatrics, Committee on Drugs. The transfer of drugs and other chemicals into human breast milk. Pediatrics.;108:776- 789. 2001.

[16] Labbok M, Krasovec K. “Toward consistency in breast-feeding definitions”. Stud Fam Plann;21:226-230. 1990.

[17] Perez-Escamilla . "Evidence Based Breast-Feeding Promotion: The Baby-Friendly Hospital Initiative1". J. Nutr. February . vol. 137 no. 2 484-487. 2007.

[18] Li R, Jewell S, Grummer-Strawn L. Maternal.” obesity and breast-feeding practices”. Am J Clin Nutr.;77 :931-936. 2003.

[19] Donath SM, Amir LH. Does maternal obesity adversely affect breastfeeding initiation and duration? J Paediatr Child Health.;36 :482- 486. 2000. 
[20]Amir LH, Donath SM. "Does maternal smoking have a negative physiological effect on breastfeeding? The epidemiological evidence". Birth. $29: 112-123.2002$.

[21] Ever-Hadani, D S Seidman, O Manor, and S Harlap, "Breast feeding in Israel: maternal factors associated with choice and duration”.J Epidemiol Community Health. Jun; 48(3): 281-285. 1994.

[22] Dewey KG1, "Nutrition, growth, and complementary feeding of the breastfed infant".Pediatr Clin North Am. Feb;48(1):87104. 2001.

[23] J Raisler, C Alexander, and P O'Campo, "Breast-feeding and infant illness: a dose-response relationship?"Am J Public Health. January; 89(1): 25-30. 1999.

[24]Chen A, Rogan W.”Breastfeeding and the risk of postnatal death in the United States". Pediatrics.2004;113 (5).

[25]Cunninghan AS, Jelliffe DB, "Jelliffe EF. Breast-feeding and health in the 1980s: a global epidemiologic review". $J$ Pediatr.;118:659-666. 1991.

[26]Raisler J, Alexander C, O'Campo P.’Breast-feeding and infant illness:a dose-response relationship". Am J Public Health.;89 :25- 30. 1999.

[27]Ball TM, Wright AL.'Health care costs of formula-feeding in the first year of life”. Pediatrics.;103:870-876. 1999.

[28]Montgomery DL, Splett PL."Economic benefit of breast-feeding infants enrolled in WIC'. J Am Diet Assoc. 97 :379- 385. 1997.

[29]Anderson JW, Johnstone BM, Remley DT."Breast-feeding and cognitive development: a meta-analysis". Am J Clin Nutr.;70 :525- 535. 1999.

[30]Ryan AS, Wenjun Z, Acosta A."Breastfeeding continues to increase into the new millennium”. Pediatrics. $110: 1103-1109$. 2002.

[31]Ahluwalia IB, Morrow B, Hsia J, Grummer-Strawn LM.'Who is breastfeeding? Recent trends from the Pregnancy Risk Assessment and Monitoring System". J Pediatr. 142 :486-491. 2003.

[32]US Department of Health and Human Services. Report of the Surgeon General's Workshop on Breastfeeding and Human Lactation. Rockville, MD: US Department of Health and Human Services, Public Health Service, Health Resources and Services Administration; DHHS Publication HRS-D-MC84 -82. 1984.

[33]US Department of Health and Human Services. Follow up Report: The Surgeon General's Workshop on Breastfeeding and Human Lactation. Rockville, MD: US Department of Health and Human Services, Public Health Service, Health Resources and Services Administration;. DHHS Publication HRS-D-MC85 -82. 1984.

[34]Spisak S, Gross S. Second Follow up Report: The Surgeon General's Workshop on Breastfeeding and Human Lactation. Washington, DC: National Center for Education in Maternal and Child Health; 1991.

[35]US Department of Health and Human Services. HHS Blueprint for Action on Breastfeeding. Washington, DC: US Department of Health and Human Services, Office on Women's Health; 2000.

[36]Cadwell K. "Reaching the goals of Healthy People 2000 regarding breastfeeding". Clin Perinatol. 26 :527-537. 1999.

[37]Kyenkya-Isabirye M. "UNICEF launches the Baby-Friendly Hospital Initiative”. MCN Am J Matern Child Nurs. 17 :177179. 1992.

[38]Lindenberger JH, Bryant CA.'Promoting breastfeeding in the WIC program: a social marketing case study". Am J Health Behav. 24 :53-60. 2000.

[39]Hartley BM, O'Connor ME. "Evaluation of the "Best Start" breast-feeding education program". Arch Pediatr Adolesc Med. $150: 868-871.1996$.

[40]Bryant CA, Coreil J, D'Angelo SL, Bailey DF, Lazarov M.”A strategy for promoting breastfeeding among economically disadvantaged women and adolescents". NAACOGS Clin Issu Perinat Womens Health Nurs. 3 :723-730. 1992.

[41]Wright AL, Bauer M, Naylor A, Sutcliffe E, Clark L. "Increasing breastfeeding rates to reduce infant illness at the community level”. Pediatrics.;101:837-844. 1998. 
[42]Ahluwalia IB, Tessaro I, Grummer-Strawn LM, MacGowan C, Benton-Davis S. Georgia's "breastfeeding promotion program for low-income women". Pediatrics. 105. 2000.

[43]Sikorski J, Renfrew MJ, Pindorai S, Wade A. "Support for breastfeeding mothers: a systematic review". Paediatr Perinat Epidemiol. $17: 407-417.2003$.

[44] Kiernan K1, Pickett KE,Soc Sci Med, "Marital status disparities in maternal smoking during pregnancy, breastfeeding and maternal depression”. Jul;63(2):335-46. 2006.

اجريت دراسة مقطعة في مدينة العلة مركز محافظة بابل وشملت ... امز اة انجبن عن طريق العملية القيصرية في مستشفى العلة التعليمي العام

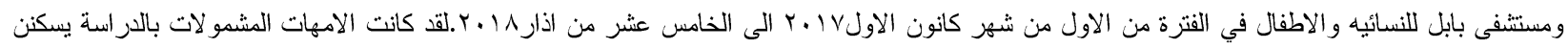

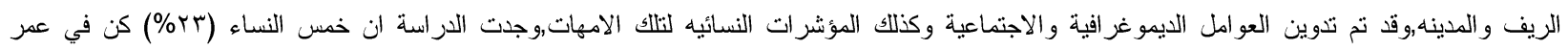
المر اهقة وقد تزوجن بعمر صغير جدا , با\% من هؤلاء النسوة كان لديهن انطباعا سلييا عن الرضاعة الطبيعية وكن يفتقرن التى التقة بالنفس وقلة التشجيع

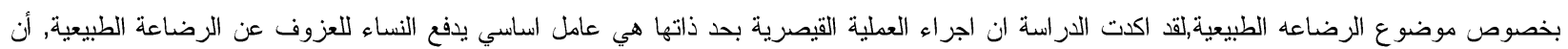
قرار العزوف عن الرضاعة الطبيعيه لم يكم فقط من ذويهن و انما ايضا من الكادر الطبي المشرف على الام بعد اجر اء العمليه القيصرية. الكلمات الدالة: الرضاعة الطبيعية، الو لادة القيصرية، حديثي الو لادة. 